\title{
Ion Current Rectification in Extra-Long Nanofunnels
}

\author{
Diego Repetto, Elena Angeli * (D), Denise Pezzuoli, Patrizia Guida, Giuseppe Firpo \\ and Luca Repetto \\ Department of Physics, University of Genoa, via Dodecaneso 33, 16146 Genoa, Italy; \\ diegorepet@gmail.com (D.R.); denise.pezzuoli@gmail.com (D.P.); patrizia.guida@unige.it (P.G.); \\ giuseppe.firpo@unige.it (G.F.); luca.repetto@unige.it (L.R.) \\ * Correspondence: elena.angeli@unige.it
}

Received: 29 April 2020; Accepted: 25 May 2020; Published: 28 May 2020

\begin{abstract}
Nanofluidic systems offer new functionalities for the development of high sensitivity biosensors, but many of the interesting electrokinetic phenomena taking place inside or in the proximity of nanostructures are still not fully characterized. Here, to better understand the accumulation phenomena observed in fluidic systems with asymmetric nanostructures, we study the distribution of the ion concentration inside a long (more than $90 \mu \mathrm{m}$ ) micrometric funnel terminating with a nanochannel. We show numerical simulations, based on the finite element method, and analyze how the ion distribution changes depending on the average concentration of the working solutions. We also report on the effect of surface charge on the ion distribution inside a long funnel and analyze how the phenomena of ion current rectification depend on the applied voltage and on the working solution concentration. Our results can be used in the design and implementation of high-performance concentrators, which, if combined with high sensitivity detectors, could drive the development of a new class of miniaturized biosensors characterized by an improved sensitivity.
\end{abstract}

Keywords: nanofunnel; FEM simulation; ionic current rectification; micro-nano structure interface

\section{Introduction}

Nanofluidics has been attracting the attention of a wide scientific community for a long time [1,2]. Nevertheless, its potential has not yet been fully exploited [3]. This interest is motivated by the fact that nanofluidic systems offer functionalities in terms of control of ionic and molecular transport that occur only at a nanoscale [4,5]. Solid-state nanopores [6] and nanochannels [7] mimicking biological counterparts [8] have been investigated and exploited in many applications [9], e.g., the detection of molecules of biomedical interest, such as proteins [10], nucleic acids [11], viruses [12-14], and nanovesicles [15] or for developing new components of ionic circuits [16], such as transistors [17], diodes [18,19], and ion pumps [20-22]. A large number of nanofluidic devices exploit electric fields for handling fluids and nano-objects near or through functional nanostructures; for this reason, understanding electrokinetic phenomena occurring at the nanoscale is of paramount importance. Many researchers focused their efforts on modeling, either by analytical or numerical methods, the electrokinetic behavior of fluids in nanoconfinement conditions or at micro-nanointerfaces [23,24], but a comprehensive understanding of all the phenomena taking place and how they influence each other is still far off. This lack of understanding is due to the complexity of the problem, which involves coupled nonlinear fluid flow, charged species transport, and a dynamic evolution of the electric field in a multi-scale space spanning from nanometers to centimeters, as stated by Han and coworkers [25]. In addition to symmetric geometries, nanopores and nanochannels with asymmetric characteristics have also been studied due to their interesting functionalities [26,27], especially when electric fields are applied. In particular, electrostatic interactions between molecules and ions in aqueous solutions, and the electric double layer 
(EDL), which forms on a nanostructure's walls, can be exploited for creating ion-selective devices [28]. Concentration polarization (CP) [29] was observed at micro-nano interfaces [30], in nanochannels [17], and in ion current rectification (ICR) in nanostructures [31] with asymmetric surface charge distribution [32,33], geometry [20,26,27,33-40], or both [41]. Concerning conical nanochannels, many different parameters, such as length, cone angle, distribution of surface charge, size and shape, were analyzed to understand how they affect CP and ICR [34,42-44]. In particular, CP has been exploited to concentrate diluted analytes, such as proteins $[29,45]$, to improve the sensitivity of biosensors. The challenging idea of combining accumulation capabilities with biological and chemical selectivity boosted the research of new methods and techniques for functionalizing the surface and/or immobilizing biomolecules. Nanochannel/nanopore surface functionalization was used for tuning the ion/molecule selectivity of the structure [46] and also for varying the rectification characteristics [46,47]. For example, Vlassiouk et al. [48] anchored biomolecules onto a conical nanopore to fabricate a biosensor for avidin, streptavidin, and immunoassays. Although research activities focused on the exploitation of $\mathrm{CP}$ for biosensing have been very intensive in recent years, as demonstrated by three recent reviews [29,45,49], the main disadvantage of CP-based accumulation systems is still the inability to precisely control the location of the preconcentrated biomolecule plug, as stated by Park and Yossifon [50]. In fact, by controlling the position of the plug it would be possible to overlap target biomolecules with probe molecules anchored on the surface to enhance the detection sensitivity and promote the recognition mechanisms.

With this idea in mind, we developed an immunosensor [51] to accumulate target biomolecules (e.g., antigens) inside a long funnel functionalized with probe molecules (e.g., antibodies). Exploiting the high surface-to-volume ratio of this structure, we succeeded in detecting, by fluorescence measurements, probe-target molecule interactions even for very dilute solutions (nearly $1 \mathrm{pg} / \mathrm{mL}$ ). Moreover, we exploited the same geometry to implement ion current rectifiers [52] and studied how analytes accumulate inside the long funnel. The promising results we obtained in both fields (immunosensing and rectifiers) motivated us to further investigate the electrokinetic phenomena occurring inside such long structures in order to further improve the combination of accumulation and detection in the same area of a device. Here, we study the distribution of ions inside an extra-long (nearly $90 \mu \mathrm{m}$ ) funnel terminating with an $80 \mathrm{~nm}$ wide and nearly $1 \mu \mathrm{m}$ long nanochannel. Our investigation was carried out by numerically solving the Poisson-Nernst-Planck equations in order to characterize the electrokinetic behavior of the structure for both positive and negative voltages and to estimate the rectification ratio $(\mathrm{RR})$ in the range $(-10,10 \mathrm{~V})$.

\section{Methods}

It is well established that the distribution of the electrical potential and the flux of each ion species due to a gradient in concentration (diffusion) and electric potential (drift) through a micro-nano fluidic device is governed by the Poisson-Nernst-Planck (PNP) equations. We solved these equations by the finite element method. Details on the implementation in the COMSOL Multiphysics ${ }^{\circledR}$ Software and on the mesh structure used in the simulations are provided in the Supplementary Materials. In the following, we provide details on the geometry that we analyzed and on the imposed boundary conditions.

\subsection{Funnel and Nanochannel Geometry}

Figure 1 shows the geometry of the device used in the numerical finite element simulations. The 3D geometry of the system (reservoir + funnel + nanochannel + reservoir) was simplified to reduce computational effort by using a $2 \mathrm{D}$ axis-symmetric geometry.

Two reservoirs $(5 \mu \mathrm{m} \times 20 \mu \mathrm{m})$, cis- on the left and trans- on the right, are connected by a funnel-shaped microchannel, $90.32 \mu \mathrm{m}$ long and $6 \mu \mathrm{m}$ wide at the base (cis-side). At the other extremity, the funnel ends with a rectangular nanochannel $(1 \mu \mathrm{m} \times 80 \mathrm{~nm})$ linked to the trans-reservoir. The total distance between the two reservoirs (funnel + nanochannel) is therefore $91.32 \mu \mathrm{m}$. This geometry was inspired by the structure used by Pezzuoli et al. [51,52]. 


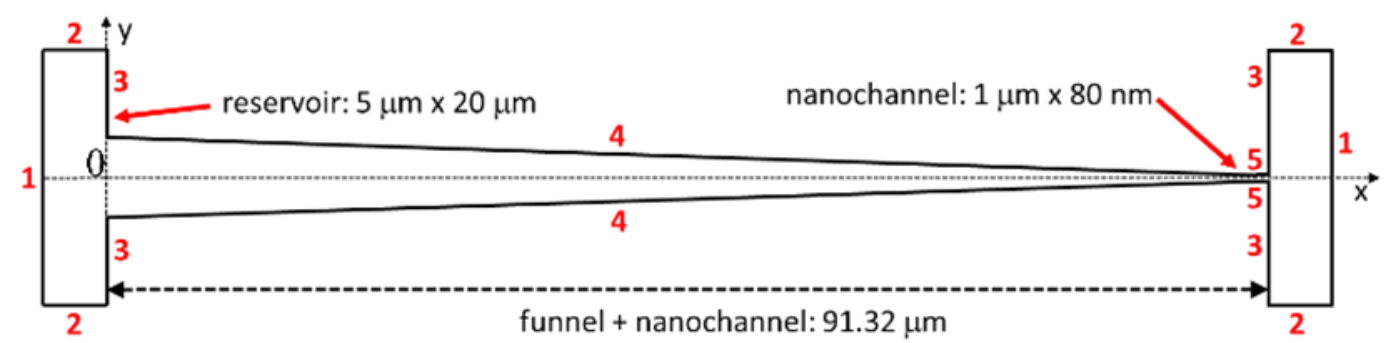

Figure 1. Sketch of the system geometry used for the FEM calculations. The red numbers correspond to walls with the same boundary conditions.

\subsection{Boundary Conditions}

We set a constant surface charge of $\sigma=-1 \mathrm{mC} / \mathrm{m}^{2}$ on the walls of the funnel and the nanochannel (labeled 4 and 5 in Figure 1). By changing the boundary conditions on wall 1 in the Poisson equation, we performed simulations for different applied voltages (V) between the cis- and trans- reservoirs. The trans-reservoir was set as grounded, while the potential for the cis- one was varied in a range of between -10 and $+10 \mathrm{~V}$. We studied the system filled with electrolytic solutions of $\mathrm{KCl}$ with different molarities $\left(1-10^{-5} \mathrm{M}\right)$. In the Nernst-Planck equations for both ion species, $\mathrm{K}^{+}$and $\mathrm{Cl}^{-}$, we set the same concentration $\mathrm{C}_{\mathrm{Bulk}}$ for boundaries 1 and 2 in both reservoirs. By solving the PNP equation system, we could model the distribution of $\mathrm{K}^{+}$and $\mathrm{Cl}^{-}$ions in the funnel and in the nanochannel as well as calculate the ionic current in the device as a function of $\mathrm{V}$ and $\mathrm{C}_{\mathrm{Bulk}}$. In principle, the set of equations that describes the physics of the system should include the Navier-Stokes (NS) equation. Without it, we are neglecting the effect of electroosmosis, which is a reasonable assumption taking into account the device dimensions and the surface charge density [53,54]. To demonstrate that this is also an acceptable approximation for our system, we performed numerical simulations with a complete PNP-NS set of equations. The results for potassium and chlorine concentrations along different sections of the device were the same, within an error of $0.1 \%$, of those calculated by PNP equations (see Supplementary Materials) for all of the six $\mathrm{C}_{\text {Bulk values }}\left(1-10^{-5} \mathrm{M}\right)$ studied.

\section{Results and Discussion}

\subsection{Accumulation}

By varying the boundary conditions for the Poisson equation at wall 1 of the cis-reservoir (wall 1 of the trans-reservoir is grounded, i.e., $\mathrm{V}=0 \mathrm{~V})$, we calculated $\mathrm{C}\left(\mathrm{K}^{+}\right)$and $\mathrm{C}\left(\mathrm{Cl}^{-}\right)$, the concentration of $\mathrm{K}^{+}$and $\mathrm{Cl}^{-}$ions, respectively, inside and at the interface of the structure as a function of the voltage applied. Positive currents $(I>0)$ flow from the wide opening towards the narrow opening of the nanochannel. With $1 \mathrm{M}$ concentration in the two reservoirs $\left(\mathrm{C}_{\mathrm{Bulk}}\right)$, an ion accumulation occurs in the funnel for negative voltages, with a peak increase in the concentration of about $0.8 \%$ in the proximity of the nanochannel entrance (Figure 2). On the other hand, an ion depletion (same "intensity" of the accumulation) occurs for positive voltages. Interestingly, at $\mathrm{C}_{\mathrm{Bulk}}=1 \mathrm{M}$ the accumulation (depletion) is independent of the sign of ion charge (Figure 2a,b).

This phenomenon is due to the presence of surface charges on the walls of the funnel and nanochannel and, consequently, to the formation of an Electric Double Layer (EDL), whose thickness, called the Debye length, $\lambda_{D}$, can be estimated as follows

$$
\lambda_{D}=\sqrt{\frac{\varepsilon k_{B} T}{2 C_{b u l k} e N_{A}}}
$$

where $k_{B}$ is the Boltzmann constant, $T$ the absolute temperature, $C_{B u l k}$ the ionic concentration of the solution, $N_{A}$ the Avogadro number, $\varepsilon$ the permittivity of free space, and $e$ the elementary charge. 


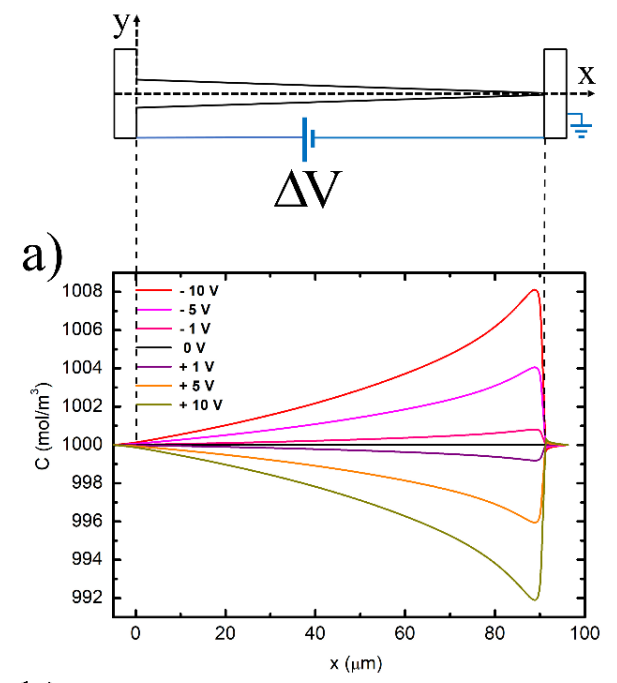

b)

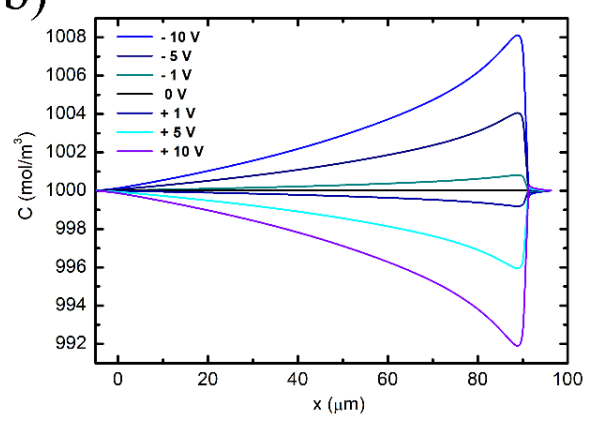

Figure 2. $\mathrm{K}^{+}(\mathbf{a})$ and $\mathrm{Cl}^{-}$(b) ion concentration along the longitudinal section of the funnel and nanochannel as a function of the applied voltage between the reservoirs $\left(C_{B u l k}=1 \mathrm{M}=10^{3} \mathrm{~mol} / \mathrm{m}^{3}\right)$.

Indeed, simulations performed considering no surface charge, i.e., $\sigma=0 \mathrm{C} / \mathrm{m}^{2}$, present a constant ion concentration along the entire device (not shown here). However, the accumulation effect at a high concentration $\left(C_{\text {Bulk }}=1 \mathrm{M}\right)$ is almost negligible, since the EDL is about $0.3 \mathrm{~nm}$, as evidenced by the constant concentration along the transversal section in the middle of the nanochannel for both ions at any applied voltage (Figure 3). Only very close to the walls (distance less than $2 \mathrm{~nm}$ ) does an increase in the $\mathrm{K}^{+}$ion concentration (a decrease for $\mathrm{Cl}^{-}$) occur.

a)

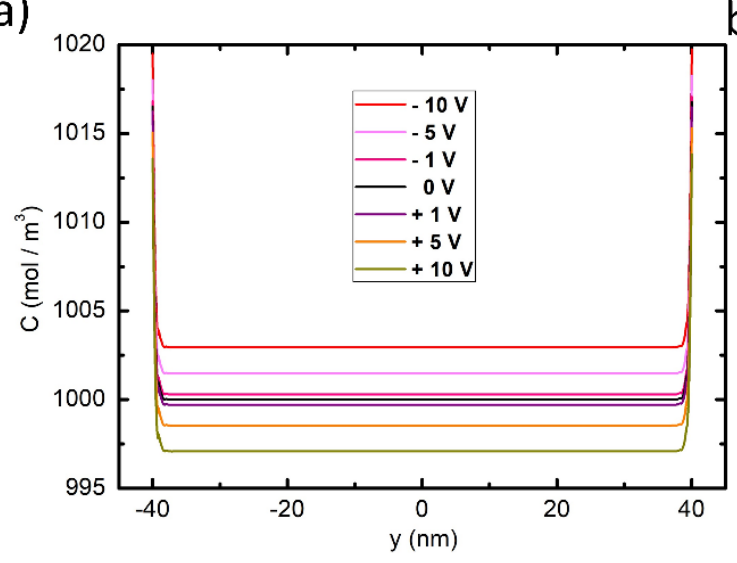

b)

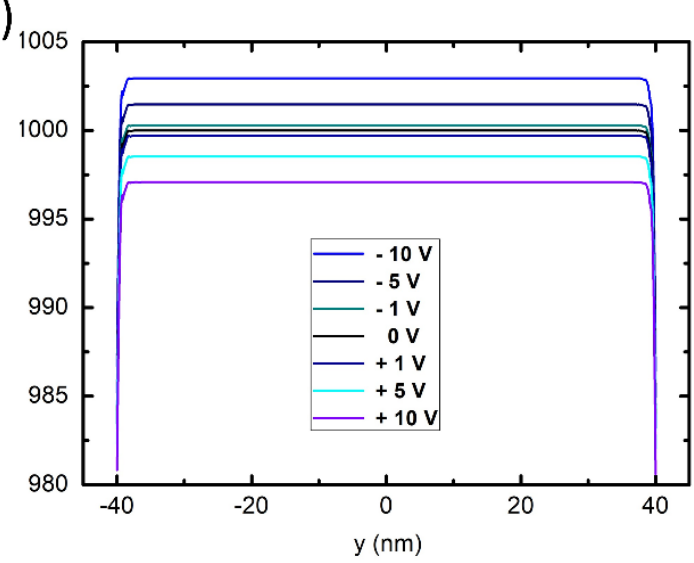

Figure 3. $\mathrm{K}^{+}(\mathbf{a})$ and $\mathrm{Cl}^{-}(\mathbf{b})$ ion concentration along the transversal section at the middle of the nanochannel as a function of the applied voltage between the reservoirs $\left(\mathrm{C}_{\mathrm{Bulk}}=1 \mathrm{M}=10^{3} \mathrm{~mol} / \mathrm{m}^{3}\right)$. 
Figure 4 shows $\mathrm{C}\left(\mathrm{K}^{+}\right)$e $\mathrm{C}\left(\mathrm{Cl}^{-}\right)$along the longitudinal section of the nanochannel. The graphs clearly indicate that there is no difference in the concentration of the two species at any applied voltage, since all curves are superimposed. The accumulation effect is strongly dependent on $\mathrm{C}_{\mathrm{Bulk}}$. By decreasing by 5 orders of magnitude the ion concentration $\left(C_{\text {Bulk }}=10^{-5} \mathrm{M}\right)$, the behavior drastically changes (Figure 5): (i) the accumulation effect in the funnel is much stronger with the maximum concentration, which is 50 times larger than $\mathrm{C}_{\mathrm{Bulk}}$; (ii) the independency from the ion charge sign is broken for positive applied voltages.

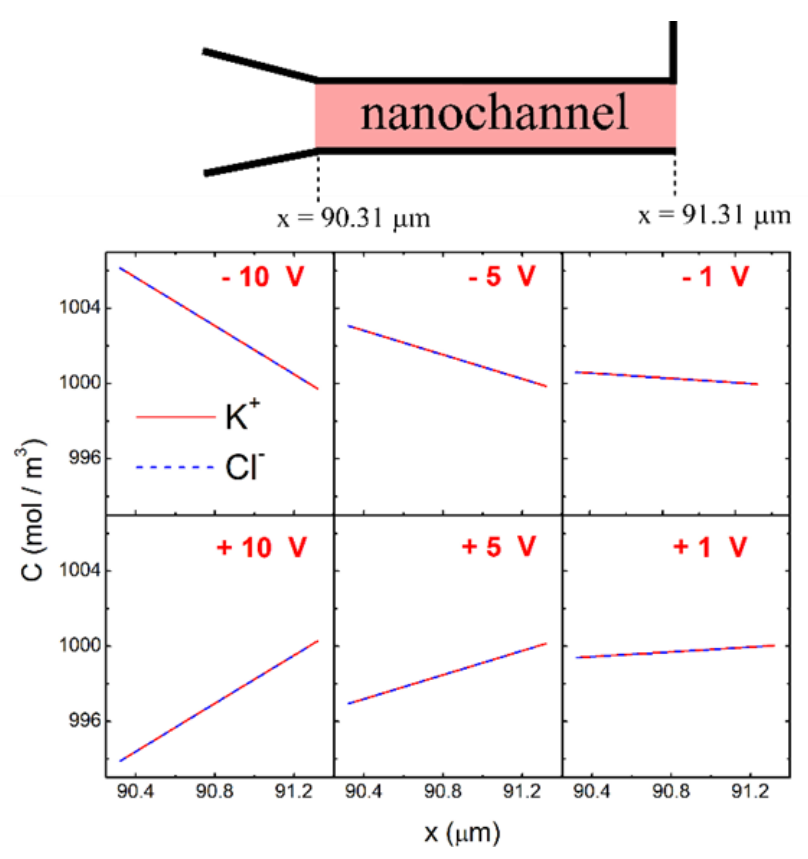

Figure 4. $\mathrm{K}^{+}$(red line) and $\mathrm{Cl}^{-}$(dashed blue line) ion concentration along the longitudinal section of the nanochannel as a function of the applied voltage between the reservoirs $\left(C_{\text {Bulk }}=1 \mathrm{M}=10^{3} \mathrm{~mol} / \mathrm{m}^{3}\right)$.

a)

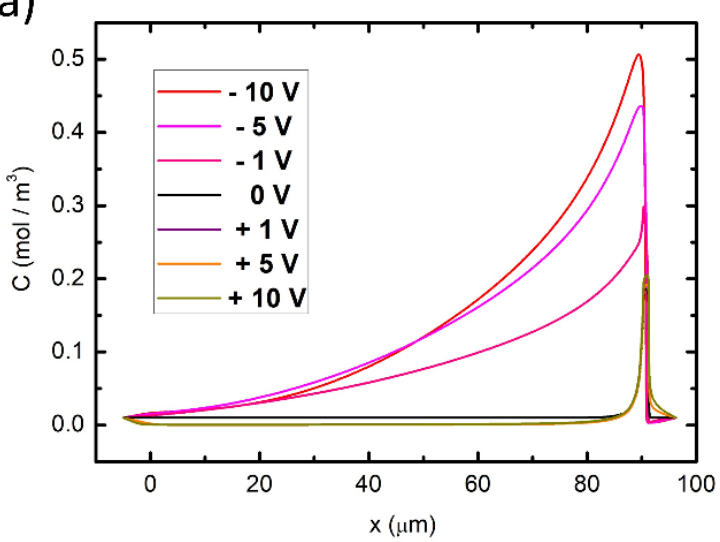

b)

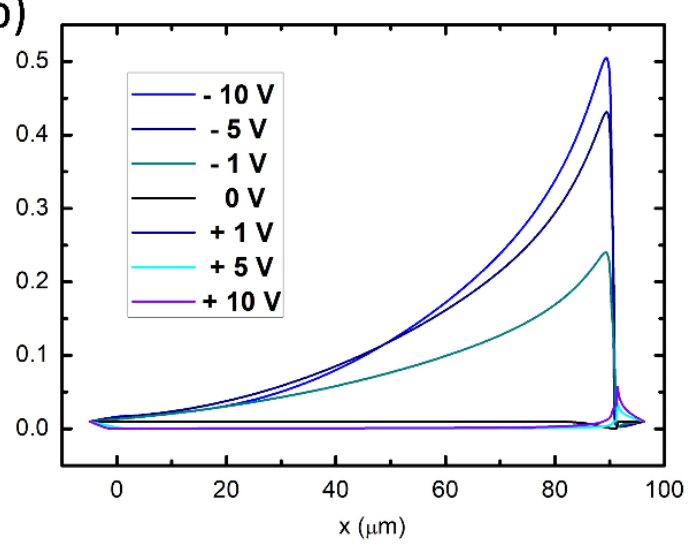

Figure 5. $\mathrm{K}^{+}(\mathbf{a})$ and $\mathrm{Cl}^{-}(\mathbf{b})$ ion concentration along the longitudinal section of the funnel and nanochannel as a function of the applied voltage between the reservoirs $\left(C_{\text {Bulk }}=10^{-5} \mathrm{M}=10^{-2} \mathrm{~mol} / \mathrm{m}^{3}\right)$.

At $C_{\text {Bulk }}=10^{-5} \mathrm{M}$, both ions are accumulated in the funnel for negative voltages, while for "zero" and positive voltages, depletion of both ions occurs. Accumulation of $\mathrm{K}^{+}$ions for "zero" and positive voltages occurs only in the nanochannel, whereas $\mathrm{C}\left(\mathrm{Cl}^{-}\right)$is very low. A zoom-in of the ion concentration as a function of the position along the longitudinal section of the nanochannel shows this clearly (Figure 6). 

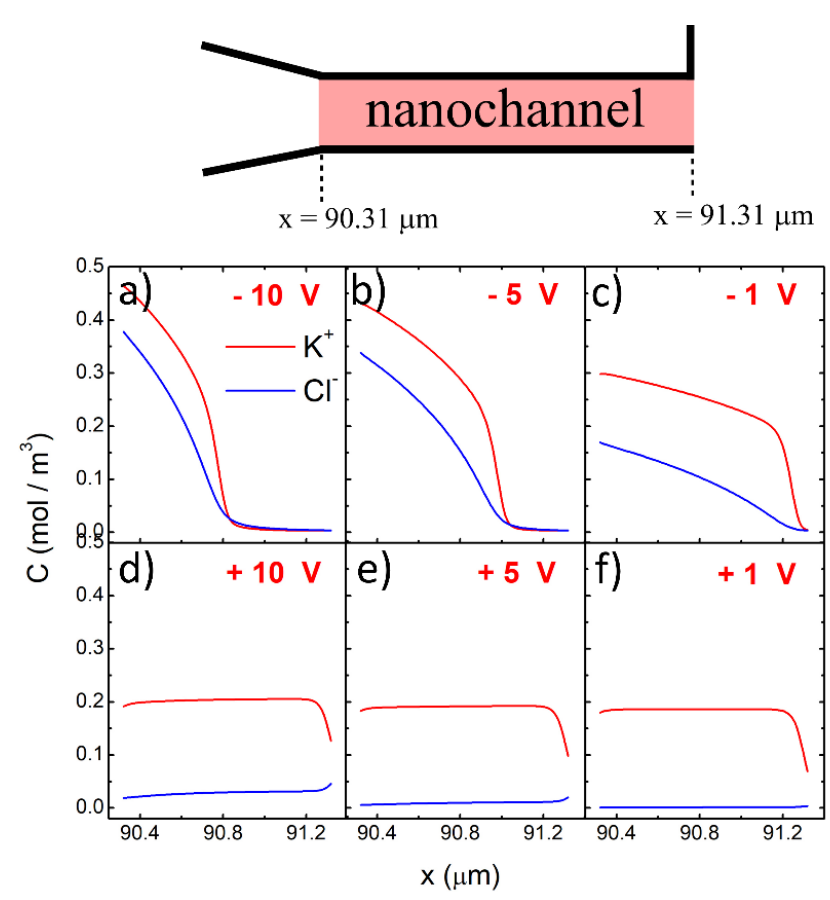

Figure 6. $\mathrm{K}^{+}$(red line) and $\mathrm{Cl}^{-}$(blue line) ion concentration along the longitudinal section of the nanochannel for different applied voltages: (a) $-10 \mathrm{~V}$, (b) $-5 \mathrm{~V},(\mathbf{c})-1 \mathrm{~V}$, (d) $10 \mathrm{~V}$, (e) $5 \mathrm{~V}$ and (f) $1 \mathrm{~V}$, between the reservoirs $\left(\mathrm{C}_{\text {Bulk }}=10^{-5} \mathrm{M}=10^{-2} \mathrm{~mol} / \mathrm{m}^{3}\right)$.

The independence of the concentration distribution from the sign of the charge is progressively broken by varying the applied voltage from -10 (Figure 6a) up to $+10 \mathrm{~V}$ (Figure 6d). At $-10 \mathrm{~V}$, both $\mathrm{C}\left(\mathrm{K}^{+}\right)$and $\mathrm{C}\left(\mathrm{Cl}^{-}\right)$are up to 40 times larger than $\mathrm{C}_{\mathrm{Bulk}}$ in the left half of the nanochannel, while both concentrations decrease to a very low value in the right half, towards the nanochannel end. This is due to the ion depletion area, which forms in the anodic reservoir around the nanochannel end. At low $\mathrm{C}_{\mathrm{Bulk}}$ and high electric potential difference between the reservoirs, the depletion area propagates into the channel, forcing the ions to accumulate in the left half of the nanochannel. By decreasing the absolute value of the applied voltage, the ion distribution becomes charge sign-dependent; while $\mathrm{K}^{+}$ions are uniformly distributed in the channel and reach a plateau for "zero" and positive voltages, $\mathrm{Cl}^{-}$are progressively dropped out (Figure $6 \mathrm{~d}-\mathrm{f}$ ). The dependency on the ion charge sign at a positive applied voltage $(+1 \mathrm{~V})$ is clearly visible in the colored plot of Figure 7: $\mathrm{C}\left(\mathrm{K}^{+}\right)$increases in the nanochannel, while for $\mathrm{Cl}^{-}$ions, the enrichment area in the cathodic side does not penetrate into the nanochannel. As we will also see in the following, in the nanochannel $\mathrm{C}\left(\mathrm{K}^{+}\right)$is constant along longitudinal sections, whereas it increases towards the negatively charged surfaces. The asymmetric response with respect to the applied voltage suggests the use of the device as a rectifier at low $C_{\text {Bulk, }}$ with an "forward state" for negative voltages and a "reverse state" for positive ones. Later on, we will further discuss this point by calculating the ionic current through the device as a function of $\mathrm{V}$ and $\mathrm{C}_{\mathrm{Bulk}}$. 


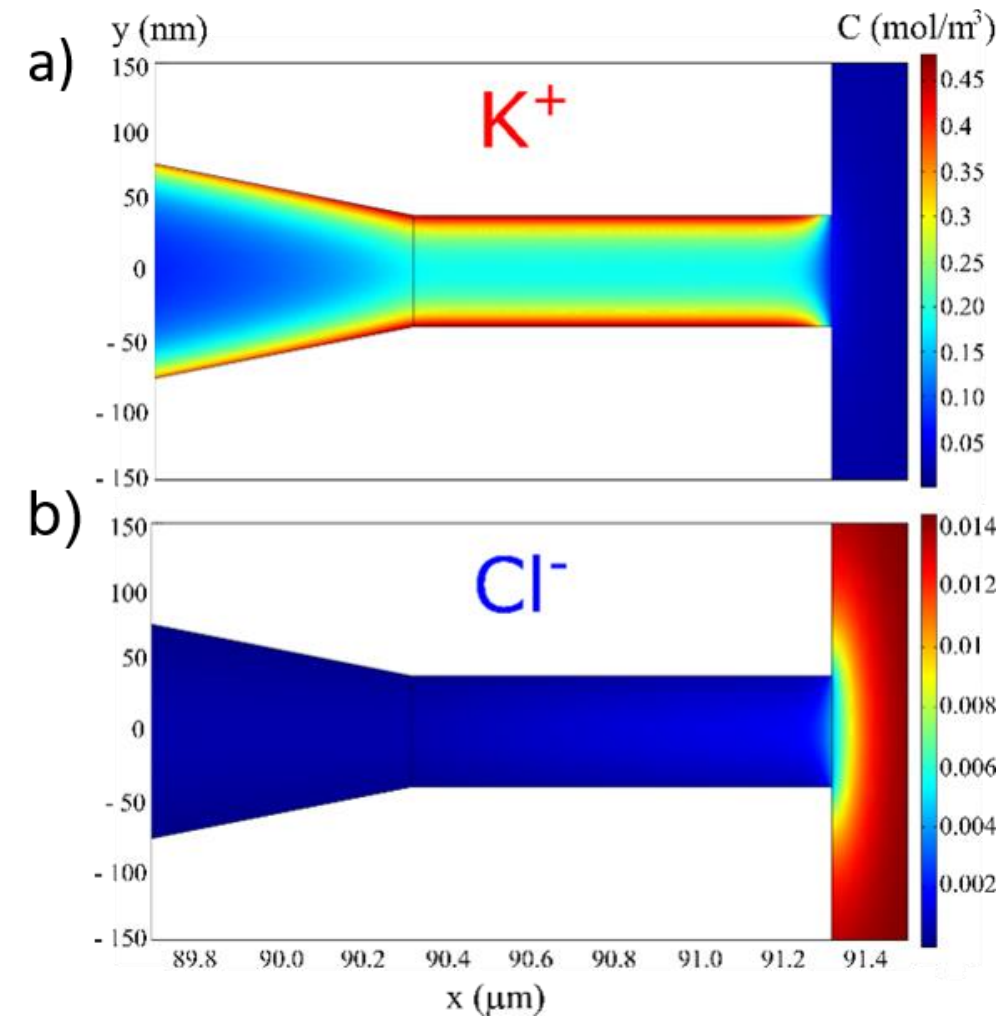

Figure 7. $\mathrm{K}^{+}(\mathbf{a})$ and $\mathrm{Cl}^{-}(\mathbf{b})$ concentrations in the nanochannel at $\mathrm{C}_{\mathrm{Bulk}} 10^{-5} \mathrm{M}\left(10^{-2} \mathrm{~mol} / \mathrm{m}^{3}\right)$, with +1 $\mathrm{V}$ applied between the reservoirs.

These results are mainly due to the large value of the Debye length for low concentration. In fact, for $C_{B u l k}=1 \mathrm{M}, \lambda_{D}=0.3 \mathrm{~nm}$, this is negligible compared with the nanochannel half-width $(40 \mathrm{~nm})$, whereas at $C_{\text {Bulk }}=10^{-5} \mathrm{M}, \lambda_{\mathrm{D}}=96 \mathrm{~nm}$, this is even larger than the width of the nanochannel itself. The increase in the Debye length when the ionic strength of the solution decreases determines an overlapping of the two EDLs in the nanochannel for a concentration lower than $10^{-3} \mathrm{M}$.

Figure 8 clearly shows that, at half the length of the nanochannel for $\mathrm{C}_{\mathrm{Bulk}}=10^{-5} \mathrm{M}$, the $\mathrm{K}^{+}$and $\mathrm{Cl}^{-}$concentrations along with the transversal section change continuously from the center to the walls of the channel, with an increase and decrease by a factor 2 for $\mathrm{C}\left(\mathrm{K}^{+}\right)$and $\mathrm{C}\left(\mathrm{Cl}^{-}\right)$, respectively. Moreover, at such a low concentration, the profile depends strongly on the applied voltage. The dependence of the ion accumulation/depletion on $C_{B u l k}$ is well described by the graphs in Figure 9 , in which the percentage increase in the ion concentration, $C_{i} / C_{B u l k}$, is plotted along the funnel for different $C_{B u l k}$ and applied voltages $\mathrm{V}$. The accumulation effect for negative voltage $(-1 \mathrm{~V})$ is strongly enhanced at low $\mathrm{C}_{\mathrm{Bulk}}$ (magenta and blue curves), but almost independent of the ion charge sign at any $\mathrm{C}_{\mathrm{Bulk}}$ (Figure $9 a, b)$. Only at very low $C_{\text {Bulk }}\left(10^{-5} \mathrm{M}\right)$ is $C\left(\mathrm{~K}^{+}\right)$larger than $C\left(\mathrm{Cl}^{-}\right)$at the funnel end. The ion depletion for positive voltage $(+1 \mathrm{~V})$ also increases at low $\mathrm{C}_{\mathrm{Bulk}}$, but in this case, the effect is charge sign dependent. While the concentration of $\mathrm{K}^{+}$ions is well below $\mathrm{C}_{\text {Bulk }}$ in the funnel, it increases in the nanochannel by a factor of 18 with respect to $C_{\text {Bulk }}$ (Figure 9c); there are only a few $\mathrm{Cl}^{-}$ions in both the funnel and the nanochannel (Figure 9d). A small increase in the $\mathrm{Cl}^{-}$ion concentration only occurs in the cathodic reservoir around the nanochannel end (enrichment area). These results are also visible in the plots in Figure 7 for a voltage applied of $+1 \mathrm{~V}$. The ion accumulation effect in the whole funnel is shown in the plot in Figure 10. Here, the $\mathrm{K}^{+}$(Figure 10a) and $\mathrm{Cl}^{-}$(Figure 10b) concentrations in the nanofluidic device at $\mathrm{C}_{\mathrm{Bulk}}=10^{-3} \mathrm{M}$ are plotted with $-10 \mathrm{~V}$ applied between the reservoirs. It is clear that the accumulation effect is independent of the ion charge sign. It should be noted that the colored scale of the two plots is different. Curves with a similar trend are reported by Liu [43] and Pietschmann [35]. The maximum concentration of positive ions is higher than the 
one of negative ions and is reached at the negatively charged walls of the funnel and nanochannel (not visible in this plot). In addition to $C_{\text {Bulk, }}$, the accumulation (for negative voltages)/depletion (for positive ones) phenomena are strongly dependent on the surface charge on the walls of the funnel and nanochannel. As mentioned before, with no surface charge, the ion concentration is constant and equal to $C_{\text {Bulk }}$ in the whole device (see Supplementary Materials).

a)

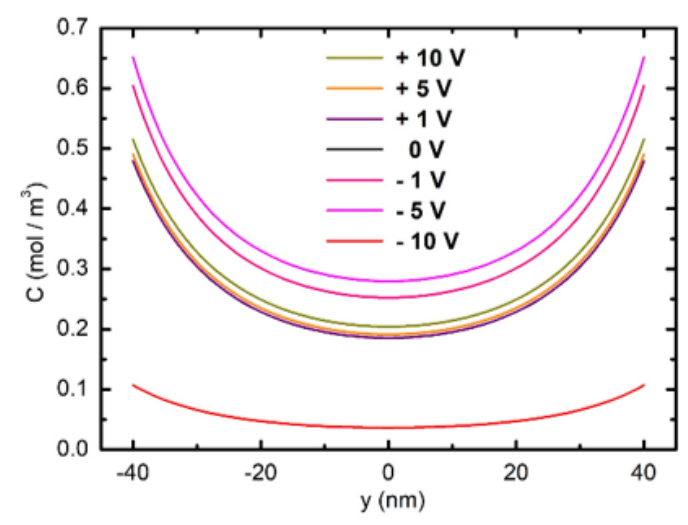

b)

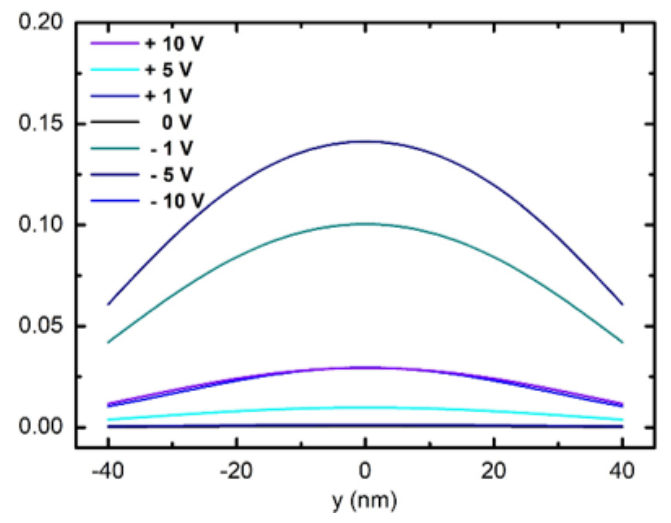

Figure 8. $\mathrm{K}^{+}(\mathbf{a})$ and $\mathrm{Cl}^{-}(\mathbf{b})$ ion concentration along the transversal section at the middle of the nanochannel as a function of the applied voltage between the reservoirs $\left(C_{\text {Bulk }}=10^{-5} \mathrm{M}=10^{-2} \mathrm{~mol} / \mathrm{m}^{3}\right)$.
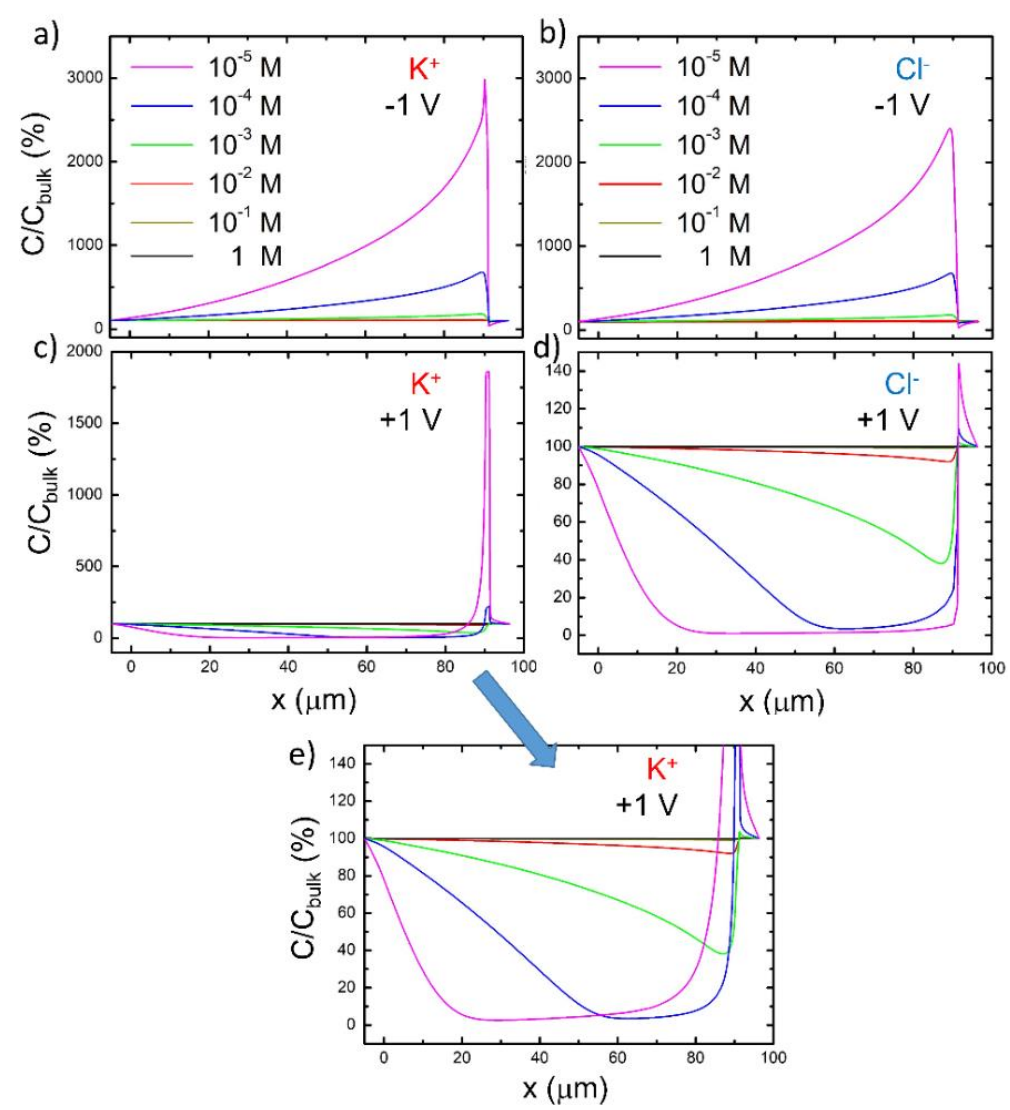

Figure 9. $\mathrm{C} / \mathrm{C}_{\mathrm{Bulk}}(\%)$ for $\mathrm{K}^{+}(\mathbf{a}, \mathbf{c})$ and $\mathrm{Cl}^{-}(\mathbf{b}, \mathbf{d})$ along the longitudinal section of the funnel and nanochannel, calculated for different $C_{\text {Bulk }}$ with $-1 \mathrm{~V}(\mathbf{a}, \mathbf{b})$ and $+1 \mathrm{~V}(\mathbf{c}, \mathbf{d})$ applied between the reservoirs. (e) Zoom-in of the graph in (c). Note the different scale on the ordinate axis. $C_{B u l k}: 1 \mathrm{M}$ (black line), $10^{-1} \mathrm{M}$ (dark yellow), $10^{-2} \mathrm{M}$ (red), $10^{-3} \mathrm{M}$ (green), $10^{-4} \mathrm{M}$ (blue), and $10^{-5} \mathrm{M}$ (magenta). 


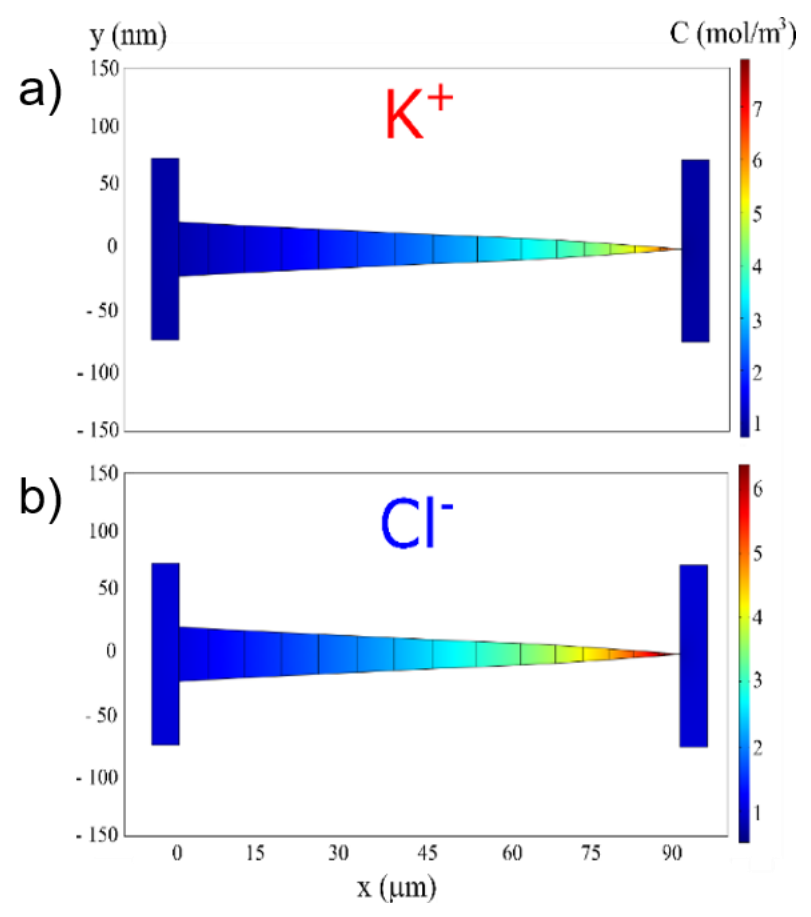

Figure 10. $\mathrm{K}^{+}$(a) and $\mathrm{Cl}^{-}(\mathbf{b})$ concentrations in the nanofluidic device at $\mathrm{C}_{\mathrm{Bulk}} 10^{-3} \mathrm{M}\left(1 \mathrm{~mol} / \mathrm{m}^{3}\right)$, with $-10 \mathrm{~V}$ applied between the reservoirs. Ion accumulation in the funnel for both ionic charges is clearly visible.

\subsection{Rectification}

As previously mentioned, at low $C_{\text {Bulk }}$ the asymmetric response of the device for positive and negative applied voltages suggests the possibility to use it as a current rectifier. In order to estimate this effect, we consider the current density $J$ at the point $(x, y)$ due to the contributions of both ion species to be

$$
J(x, y)=-D_{K} \frac{d C_{K}}{d x}+D_{C l} \frac{d C_{C l}}{d x}-\frac{F D_{K} C_{K}}{R T} \frac{d V}{d x}-\frac{F D_{C l} C_{C l}}{R T} \frac{d V}{d x}
$$

where $D_{i}$ is the diffusion coefficient and $C_{i}$ is the ionic concentration of each ion species, $F$ is the Faraday constant, and $V$ is the electrical potential. The current which flows through section $\mathrm{x}$ of the device is thus:

$$
I(x)=F \int_{-y 0}^{y 0} J(x, y) d y
$$

where the integral is calculated along the channel width, i.e., from $-y_{0}$ to $y_{0}$. Since we performed 2D simulations, the current is calculated as the amount of charge per second flowing through a segment instead of a surface and is measured in $\mathrm{A} / \mathrm{m}$. For a discrete set of data, Equation (3) can be rewritten as

$$
I(x)=F \Delta y \sum_{y} J(x, y)
$$

where $\Delta y$ is the sampling interval for $C_{i}, d C_{i} / d x$ and $d V / d x$ along the $y$-direction.

Figure 11 shows the plot of the current as a function of the applied voltage for different molarity of the $\mathrm{KCl}$ solutions. The currents have been normalized considering the concentration value in the reservoirs. At high $C_{B u l k}\left(1\right.$ and $10^{-1} \mathrm{M}$, black and dark yellow squares), the plot is symmetric with respect to the origin (i.e., no rectification). At $C_{B u l k}=10^{-2} \mathrm{M}$ (red squares), the rectification effect starts to be visible, whereas at $10^{-3} \mathrm{M}$ (green squares), the device clearly exhibits the characteristic behavior of a diode and the current flows through the device only for negative voltage. The rectification also occurs at $10^{-4} \mathrm{M}$ (blue squares), although at high voltage $(-10 \mathrm{~V})$ the effect is less pronounced than expected, 
while it decreases at $10^{-5} \mathrm{M}$ (magenta squares). The general trend of the ion current rectification ratio $\left(\mathrm{ICR}=\left|\mathrm{I}\left(\mathrm{V}_{\text {Bias }}<0\right)\right| / I\left(\mathrm{~V}_{\text {Bias }}>0\right)\right)$ is shown in Figure 12. It is clear that the ICR increases by decreasing the solution concentration (from $1 \mathrm{M}$ to $10^{-4} \mathrm{M}$ ). Below a certain concentration, the ICR also depends on the applied voltage, while at $C_{\text {Bulk }}=1 \mathrm{M}$, the ICR is about 1 at any $V_{\text {Bias, }}$, at $C_{\text {Bulk }}=10^{-3} \mathrm{M}$, the ICR is ca. 2.4 at $1 \mathrm{~V}, 11$ at $5 \mathrm{~V}$, and 20 at $10 \mathrm{~V}$. Due to the limiting-current effect, at $10^{-5} \mathrm{M}$ the ICR drops to a value of ca. 5, independently from the applied voltage. Maxima of the rectification ratio as a function of the concentration were reported in both experimental and theoretical works [38,39,44,55-58]. A similar behavior was observed by our group in devices with similar geometry [27]. According to Kovarik et al. [57], maxima occur at the bulk concentration at which the pore conductivity starts to differ significantly from the bulk, because of the contribution of surface-associated counterions to the current through the pore. For this bulk concentration, the conductivity of the pore in the "forward state" is significantly higher than in the "reverse state", resulting in a strong ICR. For lower concentrations, the conductivity values of the pore in the "forward" and "reverse" states are both dominated by the current arising from the surface charge, thus the ICR is weakened.

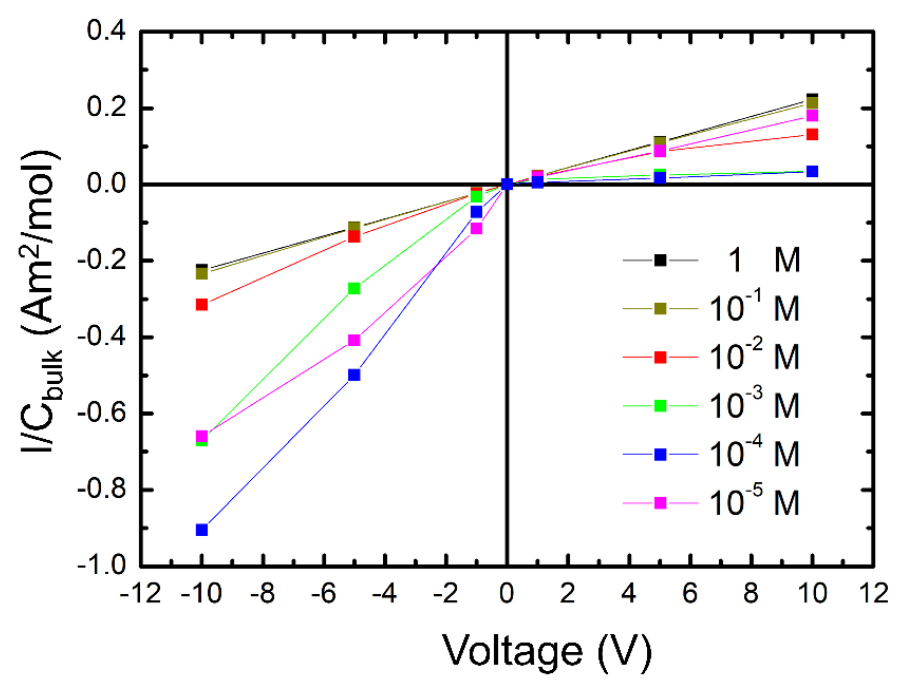

Figure 11. Current I normalized with respect to $C_{B u l k}$ as a function of the applied voltage $V$ for different values of $C_{\text {Bulk: }} 1 \mathrm{M}$ (black squares), $10^{-1} \mathrm{M}$ (dark yellow), $10^{-2} \mathrm{M}$ (red), $10^{-3} \mathrm{M}$ (green), $10^{-4} \mathrm{M}$ (blue), and $10^{-5} \mathrm{M}$ (magenta).

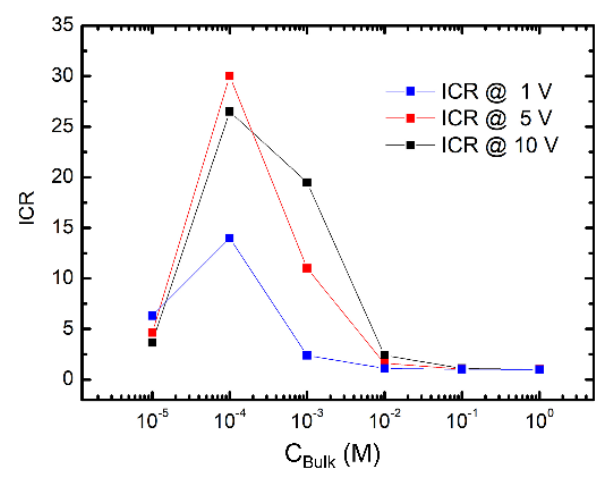

Figure 12. Current I normalized with respect to $C_{B u l k}$ as a function of the applied voltage $V$, for different values of $\mathrm{C}_{\mathrm{Bulk}}: 1 \mathrm{M}$ (black squares), $10^{-1} \mathrm{M}$ (pink), $10^{-2} \mathrm{M}$ (blue), and $10^{-3} \mathrm{M}$ (red).

Interestingly, Liu et al. [43] and Pietschmann et al. [35] calculated ion current rectification for conical structures depending on length (up to $12 \mu \mathrm{m}$ ). They found that if a conical pore is too short, 
the mechanism of ion-enrichment and depletion is too weak for a significant current rectification effect to occur. Thus, a long funnel grants strong rectification effects.

\section{Conclusions}

Numerical simulations performed on nearly $90 \mu \mathrm{m}$ long nanofunnel devices showed the versatile behavior and functional potentialities of such nanofluidic structures. Depending on the applied voltage and the ionic strength, large ion accumulation occurs along a wide area of the funnel, suggesting the use of the device in the field of high sensitivity nanosensors. Moreover, the asymmetric response for positive and negative ions confers to the device the capability of rectifying ionic currents, with a rectification ratio of up to 30 at $C_{\text {Bulk }}=10^{-4} \mathrm{M}$ and $\mathrm{V}=5 \mathrm{~V}$. These structures represent valuable tools for many fields of application, including ionic circuits. Thus, the simulation strategy that we have reported here is useful for guiding researchers in tuning the features of extra-long nanofunnels and in selecting the proper operating conditions depending on the desired electrokinetic behavior.

Supplementary Materials: The following are available online at http://www.mdpi.com/2076-3417/10/11/3749/s1, description of the equations used in the COMSOL Multiphysics ${ }^{\circledR}$ model, Figure S1: sketch of system geometry used in Comsol for the finite element calculations, Figure S2: description of the mesh used for simulations, Figure S3: comparison between the results obtained by PNP and PNP-NS equation systems, Figure S4: simulations performed considering neutral walls (no surface charge density).

Author Contributions: Conceptualization, D.R., D.P. and E.A.; methodology, D.R. and E.A.; software, D.R.; formal analysis, D.R., D.P. and E.A.; data curation, D.R.; writing-original draft preparation, D.R. and E.A.; writing-review and editing, D.P., P.G. G.F. and L.R.; supervision, L.R. All authors have read and agreed to the published version of the manuscript.

Funding: This research received no external funding.

Conflicts of Interest: The authors declare no conflict of interest.

\section{References}

1. Abgrall, P.; Nguyen, N. Nanofluidic devices and their applications. Anal. Chem. 2008, 80, 2326-2341. [CrossRef] [PubMed]

2. Kovarik, M.; Jacobson, S. Nanofluidics in Lab-on-a-Chip Devices. Anal. Chem. 2009, 81, 7133-7140. [CrossRef] [PubMed]

3. Bocquet, L. Nanofluidics coming of age. Nat. Mater. 2020, 19, 254-256. [CrossRef] [PubMed]

4. Plecis, A.; Schoch, R.; Renaud, P. Ionic transport phenomena in nanofluidics: Experimental and theoretical study of the exclusion-enrichment effect on a chip. Nano Lett. 2005, 5, 1147-1155. [CrossRef] [PubMed]

5. Schoch, R.; Han, J.; Renaud, P. Transport phenomena in nanofluidics. Rev. Mod. Phys. 2008, 80, 839-883. [CrossRef]

6. Dekker, C. Solid-state nanopores. Nat. Nanotechnol. 2007, 2, 209-215. [CrossRef]

7. Napoli, M.; Eijkel, J.; Pennathur, S. Nanofluidic technology for biomolecule applications: A critical review. Lab A Chip 2010, 10, 957-985. [CrossRef]

8. Kasianowicz, J.; Brandin, E.; Branton, D.; Deamer, D. Characterization of individual polynucleotide molecules using a membrane channel. Proc. Natl. Acad. Sci. USA 1996, 93, 13770-13773. [CrossRef]

9. Zhu, Z.; Wang, D.; Tian, Y.; Jiang, L. Ion/Molecule Transportation in Nanopores and Nanochannels: From Critical Principles to Diverse Functions. J. Am. Chem. Soc. 2019, 141, 8658-8669. [CrossRef]

10. Varongchayakul, N.; Song, J.; Meller, A.; Grinstaff, M. Single-molecule protein sensing in a nanopore: A tutorial. Chem. Soc. Rev. 2018, 47, 8512-8524. [CrossRef]

11. Wanunu, M. Nanopores: A journey towards DNA sequencing. Phys. Life Rev. 2012, 9, 125-158. [CrossRef] [PubMed]

12. de la Escosura-Muniz, A.; Merkoci, A. Nanochannels for electrical biosensing. Trac-Trends Anal. Chem. 2016, 79, 134-150. [CrossRef]

13. Harms, Z.; Mogensen, K.; Nunes, P.; Zhou, K.; Hildenbrand, B.; Mitra, I.; Tan, Z.; Zlotnick, A.; Kutter, J.; Jacobson, S. Nanofluidic Devices with Two Pores in Series for Resistive-Pulse Sensing of Single Virus Capsids. Anal. Chem. 2011, 83, 9573-9578. [CrossRef] [PubMed] 
14. Harms, Z.; Haywood, D.; Kneller, A.; Selzer, L.; Zlotnick, A.; Jacobson, S. Single-Particle Electrophoresis in Nanochannels. Anal. Chem. 2015, 87, 699-705. [CrossRef]

15. Goyal, G.; Darvish, A.; Kim, M. Use of solid-state nanopores for sensing co-translocational deformation of nano-liposomes. Analyst 2015, 140, 4865-4873. [CrossRef]

16. Han, J.H.; Kim, K.B.; Kim, H.C.; Chung, T.D. Ionic Circuits Based on Polyelectrolyte Diodes on a Microchip. Angew. Chem. Int. Ed. 2009, 48, 3830-3833. [CrossRef]

17. Daiguji, H.; Yang, P.; Majumdar, A. Ion transport in nanofluidic channels. Nano Lett. 2004, 4, $137-142$. [CrossRef]

18. Karnik, R.; Duan, C.; Castelino, K.; Daiguji, H.; Majumdar, A. Rectification of ionic current in a nanofluidic diode. Nano Lett. 2007, 7, 547-551. [CrossRef]

19. Alibakhshi, M.; Liu, B.; Xu, Z.; Duan, C. Geometrical control of ionic current rectification in a configurable nanofluidic diode. Biomicrofluidics 2016, 10, 054102. [CrossRef]

20. Siwy, Z.; Fulinski, A. Fabrication of a synthetic nanopore ion pump. Phys. Rev. Lett. 2002, 89, 198103. [CrossRef]

21. Zhang, Y.; Schatz, G.C. Advantages of Conical Pores for Ion Pumps. J. Phys. Chem. C 2017, 121, $161-168$. [CrossRef]

22. Zhang, Y.; Schatz, G.C. Conical Nanopores for Efficient Ion Pumping and Desalination. J. Phys. Chem. Lett. 2017, 8, 2842-2848. [CrossRef] [PubMed]

23. Zangle, T.A.; Mani, A.; Santiago, J.G. On the Propagation of Concentration Polarization from Microchannel-Nanochannel Interfaces Part II: Numerical and Experimental Study. Langmuir 2009, 25, 3909-3916. [CrossRef]

24. Zangle, T.A.; Mani, A.; Santiago, J.G. Theory and experiments of concentration polarization and ion focusing at microchannel and nanochannel interfaces. Chem. Soc. Rev. 2010, 39, 1014-1035. [CrossRef] [PubMed]

25. Ouyang, W.; Ye, X.; Li, Z.; Hang, J. Deciphering ion concentration polarization-based electrokinetic molecular concentration at the micro-nanofluidic interface: Theoretical limits and scaling laws. Nanoscale 2018, 10, 15187-15194. [CrossRef] [PubMed]

26. Rosentsvit, L.; Wang, W.; Schiffbauer, J.; Chang, H.C.; Yossifon, G. Ion current rectification in funnel-shaped nanochannels: Hysteresis and inversion effects. J. Chem. Phys. 2015, 143. [CrossRef] [PubMed]

27. Angeli, E.; Pezzuoli, D.; Repetto, D.; Guida, P.; Firpo, G.; Lo Savio, R.; Repetto, L.; Valbusa, U. Junction gap breakdown-based fabrication of PDMS ionic rectifiers. J. Micromechanics Microengineering 2020, 30, 025004. [CrossRef]

28. Daiguji, H. Ion transport in nanofluidic channels. Chem. Soc. Rev. 2010, 39, 901-911. [CrossRef]

29. Li, M.; Anand, R.K. Recent advancements in ion concentration polarization. Analyst 2016, 141, 3496-3510. [CrossRef]

30. Kim, S.; Song, Y.; Han, J. Nanofluidic concentration devices for biomolecules utilizing ion concentration polarization: Theory, fabrication, and applications. Chem. Soc. Rev. 2010, 39, 912-922. [CrossRef]

31. Siwy, Z.; Howorka, S. Engineered voltage-responsive nanopores. Chem. Soc. Rev. 2010, 39, 1115-1132. [CrossRef] [PubMed]

32. Stein, D.; Kruithof, M.; Dekker, C. Surface-charge-governed ion transport in nanofluidic channels. Phys. Rev. Lett. 2004, 93, 035901. [CrossRef] [PubMed]

33. van Oeffelen, L.; Van Roy, W.; Idrissi, H.; Charlier, D.; Lagae, L.; Borghs, G. Ion Current Rectification, Limiting and Overlimiting Conductances in Nanopores. PLoS ONE 2015, 10, e0124171. [CrossRef] [PubMed]

34. Perry, J.; Zhou, K.; Harms, Z.; Jacobson, S. Ion Transport in Nanofluidic Funnels. ACS Nano 2010, 4, 3897-3902. [CrossRef]

35. Pietschmann, J.F.; Wolfram, M.T.; Burger, M.; Trautmann, C.; Nguyen, G.; Pevarnik, M.; Bayer, V.; Siwy, Z. Rectification properties of conically shaped nanopores: Consequences of miniaturization. Phys. Chem. Chem. Phys. 2013, 15, 16917-16926. [CrossRef]

36. Hlushkou, D.; Perry, J.M.; Jacobson, S.C.; Tallarek, U. Propagating Concentration Polarization and Ionic Current Rectification in a Nanochannel-Nanofunnel Device. Anal. Chem. 2012, 84, 267-274. [CrossRef]

37. Xiao, K.; Xie, G.; Zhang, Z.; Kong, X.; Liu, Q.; Li, P.; Wen, L.; Jiang, L. Enhanced Stability and Controllability of an Ionic Diode Based on Funnel-Shaped Nanochannels with an Extended Critical Region. Adv. Mater. 2016, 28, 3345-3350. [CrossRef] 
38. Schiedt, B.; Healy, K.; Morrison, A.; Neumann, R.; Siwy, Z. Transport of ions and biomolecules through single asymmetric nanopores in polymer films. Nucl. Instrum. Methods Phys. Res. Sect. B Beam Interact. Mater. At. 2005, 236, 109-116. [CrossRef]

39. Kubeil, C.; Bund, A. The Role of Nanopore Geometry for the Rectification of Ionic Currents. J. Phys. Chem. C 2011, 115, 7866-7873. [CrossRef]

40. Siwy, Z. Ion-current rectification in nanopores and nanotubes with broken symmetry. Adv. Funct. Mater. 2006, 16, 735-746. [CrossRef]

41. Nguyen, G.; Vlassiouk, I.; Siwy, Z. Comparison of bipolar and unipolar ionic diodes. Nanotechnology 2010, 21, 265301. [CrossRef] [PubMed]

42. Ai, Y.; Zhang, M.; Joo, S.; Cheney, M.; Qian, S. Effects of Electroosmotic Flow on Ionic Current Rectification in Conical Nanopores. J. Phys. Chem. C 2010, 114, 3883-3890. [CrossRef]

43. Liu, Q.; Wang, Y.; Guo, W.; Ji, H.; Xue, J.; Ouyang, Q. Asymmetric properties of ion transport in a charged conical nanopore. Phys. Rev. E 2007, 75, 051201. [CrossRef] [PubMed]

44. Cervera, J.; Schiedt, B.; Neumann, R.; Mafe, S.; Ramirez, P. Ionic conduction, rectification, and selectivity in single conical nanopores. J. Chem. Phys. 2006, 124, 104706. [CrossRef] [PubMed]

45. Fu, L.M.; Hou, H.H.; Chiu, P.H.; Yang, R.J. Sample preconcentration from dilute solutions on micro/nanofluidic platforms: A review. Electrophoresis 2018, 39, 289-310. [CrossRef]

46. Lepoitevin, M.; Ma, T.; Bechelany, M.; Janot, J.; Balme, S. Functionalization of single solid state nanopores to mimic biological ion channels: A review. Adv. Colloid Interface Sci. 2017, 250, 195-213. [CrossRef]

47. Vlassiouk, I.; Siwy, Z. Nanofluidic diode. Nano Lett. 2007, 7, 552-556. [CrossRef]

48. Vlassiouk, I.; Kozel, T.; Siwy, Z. Biosensing with Nanofluidic Diodes. J. Am. Chem. Soc. 2009, 131, 8211-8220. [CrossRef]

49. Wang, C.; Wang, Y.; Zhou, Y.; Wu, Z.; Xia, X. High-performance bioanalysis based on ion concentration polarization of micro-/nanofluidic devices. Anal. Bioanal. Chem. 2019, 411, 4007-4016. [CrossRef]

50. Park, S.; Yossifon, G. Combining dielectrophoresis and concentration polarization-based preconcentration to enhance bead-based immunoassay sensitivity. Nanoscale 2019, 11, 9436-9443. [CrossRef]

51. Pezzuoli, D.; Angeli, E.; Repetto, D.; Ferrera, F.; Guida, P.; Firpo, G.; Repetto, L. Nanofluidic-Based Accumulation of Antigens for Miniaturized Immunoassay. Sensors 2020, 20, 1615. [CrossRef] [PubMed]

52. Pezzuoli, D.; Angeli, E.; Repetto, D.; Guida, P.; Firpo, G.; Repetto, L. Increased Flexibility in Lab-on-Chip Design with a Polymer Patchwork Approach. Nanomaterials 2019, 9, 1678. [CrossRef] [PubMed]

53. Vlassiouk, I.; Smirnov, S.; Siwy, Z. Ionic selectivity of single nanochannels. Nano Lett. 2008, 8, 1978-1985. [CrossRef] [PubMed]

54. Villegas, A.; Berardi, D.; Diez, F. Numerical investigation of the current transition regimes in nanochannels. Electrophoresis 2019, 40, 740-747. [CrossRef]

55. Momotenko, D.; Girault, H.H. Scan-Rate-Dependent Ion Current Rectification and Rectification Inversion in Charged Conical Nanopores. J. Am. Chem. Soc. 2011, 133, 14496-14499. [CrossRef]

56. White, H.S.; Bund, A. Ion current rectification at nanopores in glass membranes. Langmuir 2008, 24, $2212-2218$. [CrossRef]

57. Kovarik, M.; Zhou, K.; Jacobson, S. Effect of Conical Nanopore Diameter on Ion Current Rectification. J. Phys. Chem. B 2009, 113, 15960-15966. [CrossRef]

58. Ramirez, P.; Apel, P.; Cervera, J.; Mafe, S. Pore structure and function of synthetic nanopores with fixed charges: Tip shape and rectification properties. Nanotechnology 2008, 19, 315707. [CrossRef]

(C) 2020 by the authors. Licensee MDPI, Basel, Switzerland. This article is an open access article distributed under the terms and conditions of the Creative Commons Attribution (CC BY) license (http://creativecommons.org/licenses/by/4.0/). 